\title{
CORRELACIÓN UNIVERSIDAD ENSEÑANZA MEDIA
}

\section{CORRELATION UNIVERSITY HIGH SCHOOL}

José Antonio Martínez Pons: Departamento de Química Analítica e Ingeniería Química. Universidad de Alcalá de Henares. Madrid (España) joseantonio.martines@uah.es

\section{CURRÍCULUM VITAE}

Licenciado en Ciencias Físicas (Geofísica) por la Universidad Complutense de Madrid (España) y en Ciencias Químicas (Química física) por la UNED (España). Doctor por la Universidad de Alcalá de Henares (España) en el año 2000. Profesor de la Universidad de Alcalá de Henares en el área de Química analítica e Ingeniería química.

\section{RESUMEN}

Según los últimos datos e informes, la calidad académica de los alumnos que llegan a la Universidad, y de los que salen de ella, es cada vez menor. Ninguno destaca intelectualmente, ni pretende hacerlo. Su única aspiración es ganar dinero de la forma que sea. El problema surge por la falta de coordinación entre el Bachillerato y la Universidad.

\section{PALABRAS CLAVE}

Universidad - Bachillerato - Calidad - Alumnos 


\begin{abstract}
According to the latest data and reports, the academic quality of students coming to college, and coming out of it, is declining. None stands intellectually, nor is it intended to. His only ambition is to earn money as it is. The problem arises from the lack of coordination between high school and college.
\end{abstract}

\title{
KEY WORDS
}

University - Bachelor - Quality - Students

\section{TEXTO:}

Cuando los profesores comentamos la situación de nuestros alumnos, casi siempre nos quejamos de que los niveles con que llegan a la Universidad son cada día más bajos y a fortiori, los de salida también.

En los últimos tiempos tenemos datos objetivos, como los informes PISA, que nos dejan a la cola del mundo "civilizado". Por cierto, del informe PISA no me preocupa tanto el bajo nivel de nuestros estudiantes medios cuanto el bajísimo nivel de los excelentes. Está feo citarse a uno mismo, pero a un artículo publicado en estas páginas y que titulé "¿Dónde están los sobresalientes?" me remito ( $\mathrm{N}^{\mathrm{o}} 23$ de Vivat Academia). Acerté hasta en los porcentajes, lo cual no es un mérito, es un poco de estadística y teoría de muestras.

La excelencia está proscrita en todos los campos menos en el deporte y en eso que alguien, osado y sordo, llama música (de consumo, añado). 
Nuestros jóvenes no aspiran a destacar en nada intelectual, sólo aspiran a ganar dinero, cuanto más mejor, cuanto antes mejor y del modo más fácil. Así es y así lo vemos.

Un gran músico español decía el otro día que en el mundo de la lírica los chicos sólo aspiran a entrar cuanto antes en el circuito de los grandes cachés, sin pensar que para llegar a estos circuitos hacen falta unas dotes extraordinarias $y$, sobre todo, muchos años de trabajo. Si se añade un buen padrino o madrina, mejor.

La sociedad de consumo, por otra parte, construye sus ídolos, pero con la misma facilidad con que los construye los destruye, incluso físicamente. Esto es así sobre todo en el mundo del deporte, pero en muchos campos más, especialmente en las artes sin base especulativa material. En las artes plásticas, por ejemplo, nadie dudará que si galeristas, críticos y marchantes deciden crear un genio, lo crean. Lógicamente quien compre las obras de tal genio se encargara mucho de que no se devalúen, quien patrocina un disco, sin embargo, buscará lo contrario, para que se compre un disco nuevo, igual de malo.

Pero lo peor que puede ocurrir a una cultura es quedar en manos de mediocres. El mediocre se rodea de mediocres y acaba refocilándose en su mediocridad.

Por supuesto que si la mediocridad se hace dueña de la sociedad, también se hará dueña de la Universidad y lo vemos todos los días, aunque, afortunadamente, el concepto universal del saber le obliga de vez en cuando a potenciar a sus propios excelentes. Sin excederse, no se vaya a notar demasiado que hay mucho mediocre suelto.

Una prueba ad hominem, mejor ad mulierem, de lo dicho es que en España quien detenta la máxima responsabilidad en el campo de la cultura en general, además 
profesora universitaria de letras, no sepa conjugar el verbo "dico, dicere, dixi, dictum" -los de mi generación lo aprendimos en $2^{\circ}$ Bachillerato, del de entonces-, y se permita dar lecciones de democracia apoyada en su ignorancia supina o confunda un viaje de turismo avant la lettre de Don Miguel de Cervantes con su cautividad a la espera de que los frailes mercedarios le liberasen. Con todas sus pegas y corruptelas, la Universidad es tal vez el único lugar donde la cultura, -no la cultureta de "cineastillas subvencionados", novelistas de écurie de Polanco, tertulianos y demás rebaños ("gente de cultura", "trabajadores de la cultura", etc. tienen la desfachatez de autotitularse algunos de esta panda de zánganos asistidos)-, se respeta y cultiva.

Y como siempre, me estoy escapando de mi idea inicial.

Los profesores universitarios se quejan del bajo nivel con que llegan los estudiantes. Seguro que tienen razón pero yo me pregunto y pregunto: ¿No sería necesaria una eficaz coordinación entre Bachillerato y Universidad?

En este momento, y salvas algunas universidades privadas de reconocido prestigio que hacen pruebas de ingreso, en la mayoría de universidades el único filtro es la llamada "selectividad", filtro bastante inefectivo que únicamente se rige por la ley de la oferta y la demanda determinada por la nota de corte. Durante mucho tiempo, cito de memoria, la carrera con más nota era Fisioterapia, disciplina que, con todos mis respectos, más que dominio de la mecánica cuántica, requiere habilidad manual, sin embargo, últimamente, a carreras tradicionalmente difíciles, o complicadas, como algunas ingenierías o físicas se entra prácticamente con cinco pelón. Ello trae como consecuencia que, a veces, estas carreras, que exigen más esfuerzo y más continuado que otras, sean refugio de rebotados.

De todas formas, vuelvo mi argumento. 
¿Sabe la Universidad cómo le llega el alumno medio en las disciplinas que necesita? En mi opinión, muy poco. Tan sólo los coordinadores de las respectivas materias y con muchas reservas. Muchas veces los profesores de primero recuerdan sus estudios preuniversitarios, que encima diluyen en la bruma de los recuerdos y se acaban convenciendo de que los estudiantes deben saber lo que ellos creen que sabían entonces.

Sin embargo, en ocasiones se dan laudables esfuerzos por intentar, al menos, establecer unos puentes. La idea de los profesores asociados de bachillerato era una excelente idea en principio, coordinaciones periódicas, jornadas de estudio, podrían ser otras.

Sería preciso que los profesores de universidad supieran claramente en qué condiciones les llega el estudiante medio. Si estas condiciones son inaceptables, y en mi opinión lo son, se trata de buscar entre todos una solución. Si ésta requiere unos controles más serios, que se apliquen, si requiere un años más de permanencia en la EE MM, pues que se legisle en este sentido (lo veo difícil es caro y no cumple la idea de "guardería" de los políticos). Bien está que el aspirante a ingeniero aeronáutico, es un ejemplo, sepa quién era Platón, cómo evolucionó el pensamiento en la Edad Media, no haga faltas de ortografía (aunque nada menos que el Presidente de Gobierno, de letras, las comete y gordas) o recuerde la capital de Pakistán, pero más importante es que tenga unas bases matemáticas y físicas sólidas.

La directora del Instituto donde presto mis servicios me acaba de entregar una octavilla, en la que precisamente profesores de Física de una ETSI informan a los docentes de bachillerato de los conocimientos deseables para el ingreso en su escuela.

Al margen de la laudable idea, de los 14 puntos comentados, siete son simplemente matemáticas. 
Transcribo algunos

-Cálculo de integrales sencillas

-Derivadas de función y funciones compuestas. Derivadas parciales.

-Desarrollos en serie de Taylor y las aproximaciones más usuales

$$
\begin{aligned}
& \text { ó } \operatorname{sen}(\mathrm{a}) \sim \mathrm{a} a<<1 \\
& \text { ó } \cos (\mathrm{a}) \sim 1-\mathrm{a} 2 / 2 \quad \mathrm{a}<<1 \\
& \text { ó }(\mathrm{L}+\mathrm{DL})(\mathrm{H}+\mathrm{DH})(\mathrm{D}+) \sim \mathrm{LHD}(1+\mathrm{DL} / \mathrm{L}+\mathrm{DH} / \mathrm{H}+\mathrm{DD} / \mathrm{D})
\end{aligned}
$$

Análisis vectorial (aquí se piden conocimientos muy alejados de lo que está en los programas, no me pongo pesado).

Los puntos directamente relacionados con la física, hacen referencia a ideas a mi entender necesarias, pero que no aparecen en los programas, como ideas de centro de masas, concepto vectorial de la velocidad angular, análisis dimensional y homogeneidad de ecuaciones, momento de inercia...

Entienden que se incide demasiado en la mecánica estelar, consideran que el tratamiento del campo magnético es adecuado y consideran excesivo el tratamiento que se da a la óptica geométrica.

Curiosamente no hacen mención a lo poco que se estudia la termodinámica o la mecánica de fluidos, directamente relacionada con la carrera impartida en esa escuela.

Estoy convencido que, si otro centro superior hiciera un esfuerzo semejante, posiblemente hubiera un denominador común, pero lo más probable es que se sugerirían otros puntos y aspectos. Nunca se complacería a todos. 
No obstante, me ha llamado la atención que más que incidir en conocimientos de física, se incide en matemática, además sugiriendo cuestiones muy etéreas -¿Qué se entiende por integrales sencillas?- o decididamente fuera del programa de Matemáticas de EE MM. Con un canto en los dientes me daría yo si mis estudiantes fueran capaces de derivar funciones de una variable o despejar la incógnita en el exponente, para complicarles la vida con derivadas parciales.

Evidentemente, hablo del ejemplo que tengo a mano, pienso que, más o menos, lo mismo pasará en otras materias y disciplinas. También me temo que, en general, se pedirán imposibles. Creo que cualquier profesor de bachillerato contrataría a la banda del pueblo si sus alumnos supieran formular el centenar de sustancias más habituales, fueran capaces de resolver un problema estequiométrico o calcular el pH de un ácido débil monoprótico. Mi experiencia de profesor universitario me demuestra que en segundo de carrera la mayoría no son capaces de ello. Comprender lo que es el cero de un escalar es un imposible, incluso diferenciar un escalar de un vector (menos mal que mis comunicantes no me han sugerido nociones de cálculo tensorial, puestos a pedir...)

Todo me lleva a concluir que es imprescindible una coordinación UniversidadEnseñanza Media, empezando por la preparación de los programas.

Me parece también que estos programas y las exigencias de la Universidad deben ser reales $\mathrm{y}$, en última instancia, advertir a los alumnos de lo que se van a encontrar.

En fin, pienso que lo menos importante son los conocimientos concretos, sobre todo la capacidad de cálculo complicado, éstos se adquieren cuando son necesarios y se olvidan cuando no se usan, aunque yo no he olvidado la gran mayoría de conocimientos que adquirí en mi formación preuniversitaria. Claro que en mi bachillerato había exámenes trimestrales y finales y reválidas, el repaso era pues una 
herramienta manejada constantemente y esto afianzaba los saberes, habilidades y destrezas, que dicen los psico-pedagogos. Por cierto, en mis tiempos esta fauna se limitaba a pasarnos unos test una vez al año.

- ¡Lápices sobre la mesa! Empiecen a contestar -nos decía el Sr. Durán "a" Pipota, porque fumaba en pipa, que era quien nos los pasaba, con el cronómetro en la mano.

De sus resultados nunca informaron a nuestros padres, ni falta que les hacía, sobre todo al mío que, cuando llegaba el boletín, se lanzaba en picado a la nota de Matemáticas, seguía por la Física y acababa por el Latín (a él le habían suspendido alguna vez en esta materia, por eso era más tolerante), la religión, la política y la gimnasia, -como en ésta siempre tenía malas notas, bronca al canto-, si antes no había habido alguna sombra y se había quedado allí. Naturalmente, no se conformaba con el valor absoluto de la calificación, la comparaba con el mes anterior y con el resto de la clase, faltaría más. No es que fuera muy lector de Cervantes, pero tenía bien asumido aquello de poderoso es el nombre de primero.

Otra vez me he ido a mis recuerdos. ¡Qué viejo me estoy volviendo!

A lo que iba, lo que creo que deben tener los estudiantes cuando acaban el bachillero es lo que no tienen, es decir, curiosidad, espíritu de trabajo, ganas de superación y, sobre todo, ser conscientes de sus limitaciones. Si un alumno es un ignorante, por mucho que líe al profesor, la organice con el inspector, haga pliegos y más pliegos de descargo para justificar un 2 en Química (las razones para solicitar la revisión de una nota dan para escribir y una novela), sigue siendo un ignorante, como el enfermo que tiene un cáncer lo tiene independientemente del médico se lo diagnostique o no. Es bueno e imprescindible que todo el mundo tenga una idea clara de cómo acaban los estudiantes el Bachillerato, cómo ingresan en la Universidad y cuáles son los conocimientos mínimos necesarios para tal o cual carrera. Detectado el problema, se 
deberá arbitrar una solución real y factible, aunque cueste tiempo y dinero, siempre será mejor que el gran índice de abandonos y de frustraciones de tantos universitarios engañados. Un examen específico de ingreso tampoco sería mala medida, encima crearía puestos de trabajo en las Academias, ad hoc (vade retro, ya lo sé).

Todo esto está bien, pero lo que tampoco se debe hacer es ponernos a llorar sobre lo que hay. Si los estudiantes llegan a la Universidad bajo mínimos, ni se debe "abaratar" la Universidad bajando los niveles -ya está ocurriendo y los alumnos de hoy serán los profesionales de mañana-, ni caer en el otro error: "si sólo aprueba un 10 \% pues que repitan" (también ocurre). Tampoco creo que sea solución un cursillo septembrino de bases generales, aunque menos es nada. A la imaginación de los genios de la docencia dejo la solución, pero iiique se den prisa!!!

Por cierto, vaya un estrambote, el otro día me asusté al ver que una sobrina mía -vive en Palma de Mallorca y estudió en el colegio San Francisco, el mismo en que yo hice el bachillerato-, con una carrera casi terminada, no es que sea incapaz de expresarse en castellano, es iqué no lo entiende! y no es subnormal. Increíble, pero a eso vamos. Encima le han comido el coco con el catalanismo más rampante y caroteante, se le pasará, espero, y han sido ciertos cretinos universitarios los responsables. Tampoco habla otro idioma "más europeo". Todo eso llamándose Martínez y siendo biznieta de un Comandante de Infantería Española (la fiel infantería) gaditano. Triste pero cierto. 